Article

\title{
Solid-Phase Extraction of Aristolochic Acid I from Natural Plant Using Dual Ionic Liquid-Immobilized ZIF-67 as Sorbent
}

\author{
Pei Chen, Xiaoman Li, Xuemin Yan (D) and Minglei Tian*(D) \\ College of Chemistry and Environmental Engineering, Yangtze University, Jingzhou 434023, China; \\ ohne0327c@163.com (P.C.); 1xm13138462956@163.com (X.L.); XueminYan@126.com (X.Y.) \\ * Correspondence: tianm086@yangtzeu.edu.cn; Tel.: +86-7168060933
}

check for updates

Citation: Chen, P.; Li, X.; Yan, X.; Tian, M. Solid-Phase Extraction of Aristolochic Acid I from Natural Plant Using Dual Ionic LiquidImmobilized ZIF-67 as Sorbent. Separations 2021, 8, 22. https:// doi.org/10.3390/separations 8020022

Academic Editor: Gavino Sanna

Received: 6 January 2021

Accepted: 11 February 2021

Published: 18 February 2021

Publisher's Note: MDPI stays neutra with regard to jurisdictional claims in published maps and institutional affiliations.

Copyright: (c) 2021 by the authors. Licensee MDPI, Basel, Switzerland. This article is an open access article distributed under the terms and conditions of the Creative Commons Attribution (CC BY) license (https:// creativecommons.org/licenses/by/ $4.0 /)$

\begin{abstract}
Background: ZIF-67 is one of the most intriguing metal-organic frameworks already applied in liquid adsorption. To increase its adsorption performance, dual ionic liquids were immobilized on ZIF-67 in this research; (2) Methods: The obtained sorbent was used to adsorb aristolochic acid I (AAI) in standard solutions. Then, the sorbent was applied in solid-phase extraction to remove AAI from Fibraurea Recisa Pierre extracted solution. (3) Results: By analyzing the adsorption models, the highest adsorption capacity of immobilized sorbent $(50.9 \mathrm{mg} / \mathrm{g})$ was obtained at $25^{\circ} \mathrm{C}$ within $120 \mathrm{~min}$. In the SPE process, $0.02 \mathrm{mg}$ of AAI was removed per gram of herbal plant, the adequate recoveries were in the range of $96.2-100.0 \%$, and RSDs were $3.5-4.0 \%$; (4) Conclusions: The provided experimental data revealed that ZIF-67@EIM-MIM was an excellent potential sorbent to adsorb and remove AAI from herbal plant extract, and the successful separation indicated that this sorbent could be an ideal material for the pretreatment of herbal plants containing AAI.
\end{abstract}

Keywords: dual ionic liquids; metal-organic framework; aristolochic acid I; Fibraurea Recisa Pierre

\section{Introduction}

Bioactive compounds from herbal medicines are widely used; however, not all bioactive compounds in natural plants are safe. For example, Aristolochia and related plants are frequently used to cure diseases of the respiratory system in Asian countries. However, aristolochic acid I (AAI), a quite harmful compound in genus of Aristolochia plants, can cause a variety of kidney diseases and even cancer in humans [1]. The U.S. Food and Drug Administration issued a safety alert that dietary supplements or other botanicalcontaining products containing AAI have been associated with nephropathy. Wu et al. used ultra-high-performance liquid chromatography-mass spectrometer (UHPLC-HR-MS) to detect 289 samples and the results demonstrated that most representatives from the Aristolochiaceae family contain toxic AAs [2]. Hence, the AAI as a hazardous compound should be removed before using the herbal plants.

In a novel separation process, adsorption techniques using unique materials are widely applied. One of emerging porous materials is metal-organic frameworks (MOFs). They are advanced porous materials with several advantages such as simple synthesis, high porosity, and potential applications [3-5]. ZIF-67, one of the most intriguing MOF materials, exhibits excellent thermal and chemical stability due to its microporous structure, large surface area, and tunable pore aperture [6,7]. It has been fabricated in many types of porous composites and applied in electrochemistry [8], organic compounds separation [9], and adsorption [10]. Particularly in liquid-phase adsorption, ZIF-67 has attracted much attention for water purification. Lin and Chang removed malachite green from water using ZIF-67 with $2430.0 \mathrm{mg} / \mathrm{g}$ of adsorption capacity at $20{ }^{\circ} \mathrm{C}$ [11]. Yang et al. used magnetic embedded ZIF-67 to remove nitrophenol and methyl orange from water, and $52.5 \mathrm{mg} / \mathrm{g}$ and $738.0 \mathrm{mg} / \mathrm{g}$ of adsorption capacities were obtained, respectively [12,13]. Another graphene/ZIF-67 composite was applied by Yang et al. to remove ionic dyes in water, and the maximum adsorption capacity is up to $1714.2 \mathrm{mg} / \mathrm{g} \mathrm{[14].}$ 
Previous studies demonstrated that ZIF-67 was a great potential sorbent and the adsorption results on its modifications were desirable [15]. Some researchers have evaluated several modified ZIF-67 sorbents. For example, ZIF-67 was sulfureted by Liang et al. and a hollow sorbent was prepared, and the adsorption capacity $(471.7 \mathrm{mg} / \mathrm{g})$ of ciprofloxacin antibiotics was obtained on the sorbent [16]. Yang et al. synthesized a layered doublehydroxide composited ZIF-67 and applied it in $\mathrm{CO}_{2}$ adsorption with a $22.2 \mathrm{mg} / \mathrm{g}$ of adsorption capacity [17]. Zhao et al. synthesized a core-shell ZIF-67@ZIF-8 sorbent and obtained a $101.9 \mathrm{mg} / \mathrm{g}$ of adsorption capacity of Rhodamine $B$ in aqueous solution [18]. Knebel et al. applied ZIF-8-on-ZIF-67 membrane in $\mathrm{H}_{2} / \mathrm{CO}_{2}$ gas separation [19].

Ionic liquids (ILs) are recognized as green solvents, and have been used in efficient extraction or sorbent modification. IL has some unique physicochemical properties, such as negligible vapor pressure, wide chemical and electrochemical windows, non-flammability, tunable viscosity, and miscibility with several inorganic/organic solvents, which make them potential replacements for organic solvents in several areas [20,21]. One of the IL applications is the sorbent modifier. When the ILs are modified on the surface of sorbents, their hydrophilicity/hydrophobicity properties with different cations or anions can provide various chemical bonds (hydrogen, ionic, $\pi-\pi$, et al.), which create chemisorption during the adsorption process, and increased the interactions between sorbents and target compounds [22]. Two methods such as impregnation and chemical modification were used to prepare modified sorbents. In the preparation of an impregnated sorbent, IL and substrate were mixed and stirred in a solvent for several hours. The process was quite simple, but the bonds were mainly van der Waals force or hydrogen bonds, which were neither strong nor stable enough [23]. Hence, some researchers preferred the chemical modification of sorbents by covalent bonding of IL $[24,25]$.

Based on the properties of ILs, some published literature exhibited modification of ILs on MOFs and application in toxic compounds adsorption. Khan et al. introduced a typical IL 1-butyl-3-methylimidazolium chloride to MIL-101 (IL/MIL101) and applied it to adsorb benzothiophene and dibenzothiophene [26]. Sarker et al. obtained the IL (1-butyl3-methylimidazolium bromide) incorporated ZIF-8 sorbent to remove herbicides from water [27]. Liu et al. also introduced (N-butyl pyridinium bis (trifluoromethyl sulfonyl) imide) ([Bpy][NTf 2$]$ ) and tested it by $\mathrm{I}_{2}$ adsorption [28]. Gutiérrez-Serpa et al. summarized several MOF (MIL-100, MIL-101, ZIF-8, and ZIF-67) introduced ionic liquid composites in determination of alkaloids, herbicides, and pesticides [29].

However, there is no report about the application of dual ionic liquid-immobilized ZIF-67 to adsorb and remove AAI. Hence, in this research, three dual IL-immobilized ZIF-67 sorbents were synthesized and the adsorption capacities of AAI on them were evaluated. Finally, the sorbent was applied in SPE to remove AAI from Fibraurea Recisa Pierre extracted solution.

\section{Materials and Methods}

\subsection{Chemicals}

Cobalt-nitrate hexahydrate $\left(\mathrm{Co}\left(\mathrm{NO}_{3}\right)_{2} \cdot 6 \mathrm{H}_{2} \mathrm{O}\right)$, imidazole $(99.0 \%)$, 1-methylimidazole (99.0\%), 1-ethylimidazole (98.0\%), 1,2-dichloroethane (99.0\%), 1-bromo-2,5-pyrrolidinedione (NBS), aristolochic acid (98.0\%) were purchased from Aladdin Inc. (Shanghai, China). HPLC grade acetonitrile and methanol were obtained from CINC High Purity Solvents Co. Ltd. (Shanghai, China). Ethanol, triethylamine, azobisisobutyronitrile (AIBN) were obtained from Beilian Company (Tianjing, China) and their purities were higher than $99.0 \%$. Ultrapure water was produced from a purification machine (UPH-I-5, Youpu, China).

\subsection{Apparatus}

Scanning electron microscopy (SEM) images were obtained using a MIRA3 scanning microscope (TESCAN, Brno, Czech Republic). Fourier transform infrared (FT-IR, Nicolet 6700, Thermo Fisher, Waltham, MA, USA) spectroscopy was performed using KBr pellets in the range of $400.0-4000.0 \mathrm{~cm}^{-1}$ with a scan rate of $20.0 \mathrm{scans} / \mathrm{min}$. Thermogravimetric 
analysis (Labsys evo, Setaram, Caluire, France) was used with a heating rate of $10{ }^{\circ} \mathrm{C} / \mathrm{min}$ under $\mathrm{N}_{2}$. The powder X-ray diffraction (XRD) patterns were performed on an Empyrean diffractometer (Malvern Panalytical, Eindhoven, Netherlands) at room temperature using $\mathrm{Cu}$ radiation $(60.0 \mathrm{kV}$ and $55.0 \mathrm{~mA})$ over the range $5.0-60.0^{\circ}$ for characterizing the crystalline structure.

The analysis was performed on a TC-C18 column $(4.6 \times 250.0 \mathrm{~mm}, 5.0 \mu \mathrm{m}$, Agilent, Santa Clara, CA, USA) with a HPLC (LC3000, CXTH, Beijing, China). The mobile phase, flow rate, UV wavelength, injection volume and column oven temperature were acetonitrile/water (50.0:50.0, $v / v$, containing 1.0\% vol. acetic acid), $0.8 \mathrm{~mL} / \mathrm{min}, 250.0 \mathrm{~nm}, 5.0 \mu \mathrm{L}$ and $35^{\circ} \mathrm{C}$, respectively.

\subsection{Preparation of ZIF-67, ZIF-67@Br and ZIF-67@Imidazole}

ZIF-67 was prepared based on a previous reported method with modifications [3]. Cobalt-nitrate hexahydrate $\mathrm{Co}\left(\mathrm{NO}_{3}\right)_{2} \cdot 6 \mathrm{H}_{2} \mathrm{O}(1.5 \mathrm{~g})$ and 2-methylimidazole $(6.6 \mathrm{~g})$ were dissolved in $100.0 \mathrm{~mL}$ of methanol, respectively. The $\mathrm{Co}\left(\mathrm{NO}_{3}\right)_{2} \cdot 6 \mathrm{H}_{2} \mathrm{O}$ solution was slowly added into the 2-methyimidazole solution. The resulting mixture was stirred for $8 \mathrm{~h}$ and aged for $16 \mathrm{~h}$ at the ambient temperature. After that, the precipitate ZIF-67 was collected by centrifugation and washed repeatedly by methanol for three times, and dried at $60{ }^{\circ} \mathrm{C}$ for $12 \mathrm{~h}$. Finally, $7.7 \mathrm{~g}$ of ZIF-67 can be obtained.

NBS (7.4 g) was dispersed in $200.0 \mathrm{~mL}$ of dichloromethane with the assistance of ultrasonication. Then, the solution was mixed with $6.7 \mathrm{~g}$ of ZIF- 67 and $0.3 \mathrm{~g}$ of AIBN in a $250.0 \mathrm{~mL}$ flask and stirred at $45^{\circ} \mathrm{C}$ for $12 \mathrm{~h}$. The solid brominated product (ZIF-67@Br) was collected by centrifugation. After rinsing with dichloromethane for four times, the $13.6 \mathrm{~g}$ of ZIF-67@Br was obtained after drying at $40{ }^{\circ} \mathrm{C}$ for $24 \mathrm{~h}$.

Then, the imidazole modified ZIF-67 (ZIF-67@imidazole) was obtained by the reaction of ZIF-67@Br (12.5 g) and imidazole (3.2 g) in ethanol at $70{ }^{\circ} \mathrm{C}$ for $8 \mathrm{~h}$. The final product $(11.4 \mathrm{~g})$ was collected by centrifugation and washed repeatedly with ethanol, and dried at $70{ }^{\circ} \mathrm{C}$ for $12 \mathrm{~h}$.

\subsection{Synthesis of the Three ZIF-67@EIM-ILs}

Figure 1 shows the synthesis process of three sorbents. ZIF-67@imidazole (7.5 g) and 1,2-dichloroethane $(4.7 \mathrm{~g})$ were reacted at $75^{\circ} \mathrm{C}$ in $200.0 \mathrm{~mL}$ ethanol for $8 \mathrm{~h}$. After reaction, $10.6 \mathrm{~g}$ of the chlorinated ethylimidazole modified ZIF-67 (ZIF-67@EIM-Cl) was washed by ethanol and dried at $70{ }^{\circ} \mathrm{C}$ for $12 \mathrm{~h}$. Finally, three dual ILs modified ZIF-67 sorbents were obtained by the reaction of ZIF-67@EIM-Cl (3.5 g) with imidazole (1.1 g), 1-methylimidazole $(1.4 \mathrm{~g})$ and 1-ethylimidazole $(1.6 \mathrm{~g})$ in $50.0 \mathrm{~mL}$ ethanol at $75^{\circ} \mathrm{C}$ for $8 \mathrm{~h}$, respectively. After washing by ethanol, $4.0 \mathrm{~g}$ of ZIF-67@EIM-IM, $4.0 \mathrm{~g}$ of ZIF-67@EIM-MIM, and $4.2 \mathrm{~g}$ of ZIF-67@EIM-EIM were dried at $70^{\circ} \mathrm{C}$ for $12 \mathrm{~h}$.

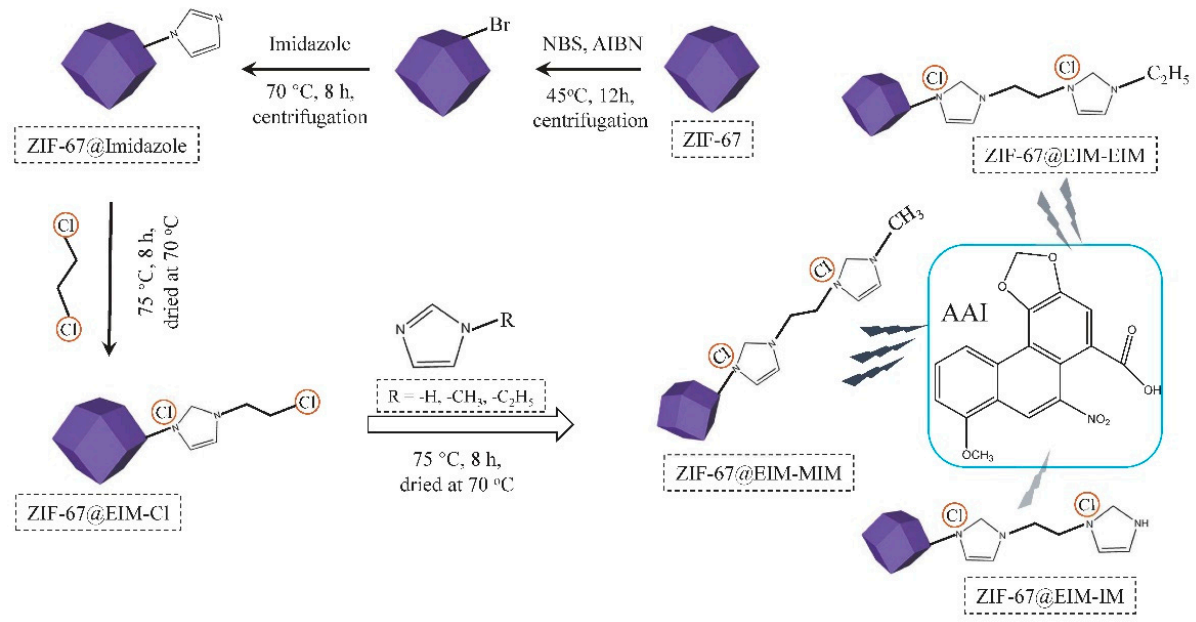

Figure 1. Synthesis process of dual IL-immobilized ZIF-67 sorbents. 


\subsection{Adsorption Isothermal and Kinetics Studies}

For the adsorption isothermal study, $0.005 \mathrm{~g}$ of ZIF-67, ZIF-67@EIM-IM, ZIF-67@EIMMIM, ZIF-67@EIM-EIM was immersed in $4.0 \mathrm{~mL}$ of AAI methanol solution with concentration in the range of $1.2-132.1 \mathrm{mg} / \mathrm{L}$ at $5,25,35$ and $45^{\circ} \mathrm{C}$. After $20 \mathrm{~h}$, the solutions after adsorption were filtered with $0.2 \mu \mathrm{m}$ Millipore membrane and the concentrations of AAI were determined. The adsorption amount was calculated according to Equation (1) and the adsorption efficiencies were obtained using different concentrations with Equation (2). Additionally, the adsorption mechanism was investigated using the adsorption capacity from the Langmuir model (Equation (3)) and Freundlich model (Equation (4)).

$$
\begin{gathered}
Q_{e}=\frac{\left(C_{0}-C_{e}\right) \times V}{m} \\
E R(\%)=\frac{\left(C_{0}-C_{e}\right) \times V}{C_{0} \times V} \times 100 \% \\
\frac{C_{e}}{Q_{e}}=\frac{1}{Q_{\max } K_{L}}+\frac{C_{e}}{Q_{\max }} \\
Q_{e}=K_{F} \times C_{e}^{\frac{1}{n}}
\end{gathered}
$$

where $Q_{e}(\mathrm{mg} / \mathrm{g})$ is the adsorption capacity of AAI adsorbed onto sorbent at equilibrium. $C_{0}$ and $C_{e}(\mathrm{mg} / \mathrm{mL})$ are the initial concentrations and equilibrium concentrations after adsorption, respectively. $V(\mathrm{~mL})$ is the solution volume and $m(\mathrm{~g})$ is the weight of the sorbents. $E R(\%)$ is the adsorption efficiency. The Langmuir parameters $K_{L}(\mathrm{~L} / \mathrm{mol})$ is related to the adsorption rate and $Q_{\max }(\mathrm{mg} / \mathrm{g})$ is the adsorption capacity. The Freundlich constant $\mathrm{n}$ is related to the heterogeneity of the adsorption and KF is the adsorption capacity of the adsorbent.

For the adsorption kinetics study, 0.005 g of ZIF-67, ZIF-67@EIM-IM, ZIF-67@EIMMIM, ZIF-67@EIM-EIM was immersed in $4.0 \mathrm{~mL}$ of AAI methanol solution with three initial concentrations of $15.0,65.0$ and $100.0 \mathrm{mg} / \mathrm{L}$ at $25^{\circ} \mathrm{C}$ with different time in the range of 1.5-1200.0 min. Then, the pseudo-first-order (Equation (5)) and pseudo-second-order (Equation (6)) kinetics models were used to fit the experimental data to evaluate the kinetics of the adsorption process.

$$
\begin{gathered}
\ln \left(Q_{e}-Q_{t}\right)=\ln Q_{e}-k_{1} t \\
\frac{t}{Q_{t}}=\frac{1}{k_{2} Q_{e}^{2}}+\frac{t}{Q_{e}}
\end{gathered}
$$

$Q_{t}(\mathrm{mg} / \mathrm{g})$ is the amount of AAI adsorbed at different times. $k_{1}(1 / \mathrm{min})$ and $k_{2}(\mathrm{~g} / \mathrm{mg} \cdot \mathrm{min})$ are the rate constants for pseudo-first-order and pseudo-second-order models, respectively.

\subsection{Solid-Phase Extraction of AAI from Fibraurea Recisa Pierre}

First, $0.5 \mathrm{~g}$ of Fibraurea Recisa Pierre powder was dipped into $4.0 \mathrm{~mL}$ of methanol for $8 \mathrm{~h}$ at room temperature. The extracted solution was obtained after it was filtered with $0.2 \mu \mathrm{m}$ Millipore membrane. A SPE cartridge $(\varnothing 0.9 \mathrm{~cm})$ was fixed in a closed container at a certain temperature, $0.05 \mathrm{~g}$ of ZIF-67@EIM-IL sorbent was packed into it and pretreated with $4.0 \mathrm{~mL}$ of methanol. Then the extracted solution was poured into the cartridge and the solution from the cartridge bottom was collected. The flow was controlled as $0.2 \mathrm{~mL} / \mathrm{min}$ and the collected solution was poured back into the cartridge. After 8 times repetitions, hexane, water, methanol, and methanol/0.1 M aqueous $\mathrm{NaOH}(90.0: 10.0, v / v)$ with different elution abilities were used to separate AAI from interferences with a flow $1.0 \mathrm{~mL} / \mathrm{min}$.

\section{Results and Discussions}

\subsection{Characterization}

The results of SEM analyses of the synthesized composites are presented in Figure 2. In Figure 2A, ZIF-67 showed a regular polygon-shape with a mean diameter of about 
$180.0 \mathrm{~nm}$. When the IL was immobilized, the polygon-shape of ZIF-67 was covered (Figure 2B) and the average diameter was slightly increased to $195.0 \mathrm{~nm}$ according to the scale-plate in the images. After the aggregation of dual ILs on ZIF-67, the irregular surface of sorbent was observed and the average diameter increased to $245.0 \mathrm{~nm}$ (Figure 2C). In Figure S1, the variation tendencies of surface and diameter were also observed on other ILs-immobilized sorbents.

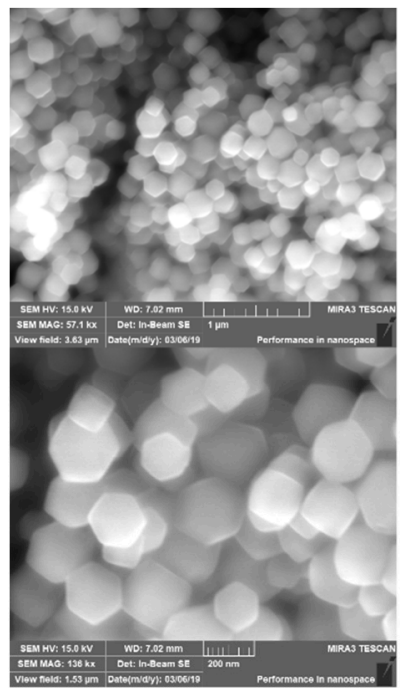

(A)

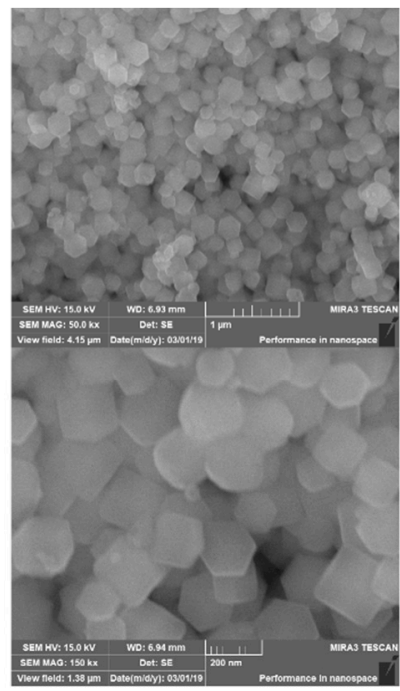

(B)

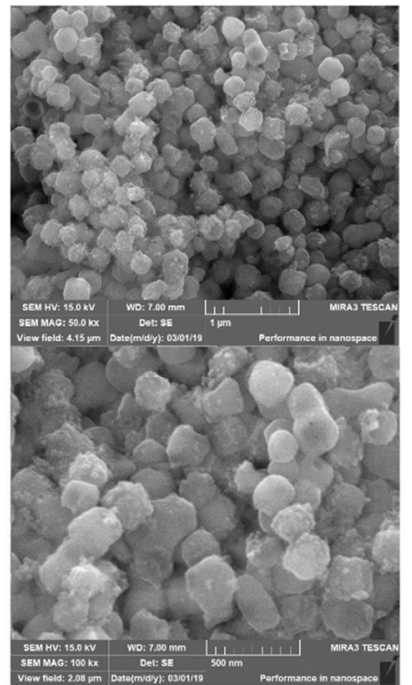

(C)

Figure 2. SEM of ZIF-67 (A), ZIF-67@EIM-Cl (B) and ZIF-67@EIM-MIM (C) with different scales.

The FT-IR of all materials in Figure S2 showed a wide peak at $1400.3 \mathrm{~cm}^{-1}$ belongs to the imidazole group in ZIF-67. The -Cl peak (belongs to 1,2-dichloroethane) at $668.0 \mathrm{~cm}^{-1}$ and $-\mathrm{C}-\mathrm{N}$ peaks $\left(1165.8 \mathrm{~cm}^{-1}\right.$ and $\left.1235.1 \mathrm{~cm}^{-1}\right)$ proved that the IL was immobilized on ZIF-67. Dual ILs-immobilized ZIF-67 had larger peak area of -C-N than ZIF-67@EIM-Cl because of the double imidazole groups. More peaks of carbon chain bending appeared at $1087.2 \mathrm{~cm}^{-1}$ proved that dual ILs were immobilized. Additionally, among the three dual ILs (EIM-IM, EIM-MIM and EIM-EIM), -C-H group on the outlay of dual IL EIM-EIM was larger than the other two, so the peak in the range of $1450.5-1502.2 \mathrm{~cm}^{-1}$ had the largest area.

TGA can determine the thermal degradation of ZIF-67 and immobilized ILs. Some results of sorbents are shown in Figure S3. From $400{ }^{\circ} \mathrm{C}$ to $800{ }^{\circ} \mathrm{C}, 1.1 \mathrm{mg}, 1.4 \mathrm{mg}$ and $2.1 \mathrm{mg}$ weight loss were observed for ZIF-67, ZIF-67@EIM-Cl and ZIF-67@EIM-MIM, respectively. ZIF- 67 decomposed obviously above $400{ }^{\circ} \mathrm{C}$ due to the decomposition of the ligand, an extra weight loss was observed for ZIF-67@EIM-Cl could be resulted from the decomposition of C-C bond [30]. Similar tendency of ZIF-67@EIM-MIM were observed and more weight loss could be corresponded to decomposition of more $\mathrm{C}-\mathrm{C}$ bonds.

After imidazole and ILs-immobilized on ZIF-67, the XRD spectrogram showed several weak peaks were also detected at $2 \theta$ values which were matching to ZIF-67 (Figure S4). After immobilization, the peaks were mostly weakened conforming the structure of the functional layers placed on the surface of ZIF-67.

\subsection{Adsorption Isothermal and Kinetics Studies on the Three ZIF-67@EIM-ILs}

The isothermal adsorption is used to explain the relationship between the adsorption capacity of adsorbent and the adsorbates concentration when the adsorption is equilibrium at a fixed temperature. The adsorption capacities of AAI onto the three dual IL-immobilized ZIF-67 sorbents at four temperatures $\left(5,25,35\right.$ and $\left.45^{\circ} \mathrm{C}\right)$ are shown in Figure 3 . According to the molecular structure of $\mathrm{AAI},-\mathrm{O}-$ and $-\mathrm{NO}_{2}$ groups could create a weak hydrogen bond and $-\mathrm{COOH}$ was an electron-withdrawing group, so it could form strong hydrogen 
bonds with IL. The physicochemical characteristic of AAI (pKa value is 3.3) dominated its anionic form in methanol solution at natural $\mathrm{pH}$, so the ionic interaction between IL and AAI resulted higher concentration of AAI on sorbents [31]. AAI also contained hydrophobic phenanthrene rings and a $-\mathrm{OCH}_{3}$ group. The phenanthrene ring interacted with ILs by $\pi-\pi$ bond and $-\mathrm{OCH}_{3}$ group interacted with the carbon chain of IL due to the low polarity. The polarity of the out-layer IL decreased with carbon chain length increasing. The optimum equilibrium of the interaction and hydrophobic property of AAI was obtained on methylimidazole group of the out-layer IL. So ZIF-67@EIM-MIM had higher adsorption amount than the other two sorbents.
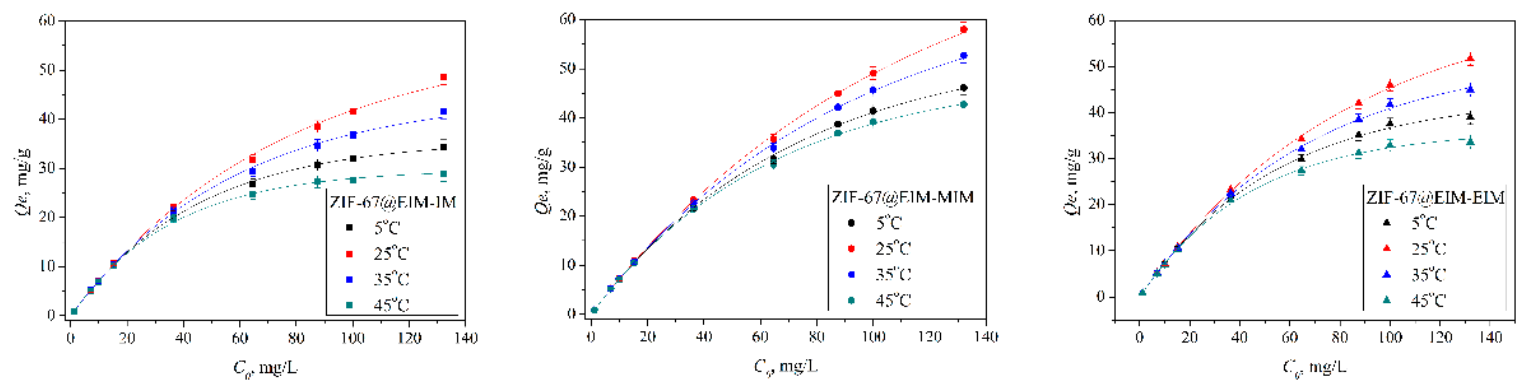

Figure 3. The relationships between initial concentration $\left(C_{0}\right)$ and adsorption amount $\left(Q_{e}\right)$ of AAI on three sorbents at 5,25 , 35 and $45^{\circ} \mathrm{C}$.

Figure S5 showed the relationship between $C_{0}$ and adsorption efficiency $E R(\%)$. It was observed that with the fixed volume of solution, the saturation of the sorbents was achieved more easily at a higher initial concentration, so the ER (\%) was lowered with the increasing initial concentration. In addition, the adsorption amounts on all sorbents increased from 5 to $25^{\circ} \mathrm{C}$, and then decreased when the temperature was over $25^{\circ} \mathrm{C}$. This is because at a low temperature, motion of the molecules was too slow to obtain a fully adsorption. Then the temperature over $25^{\circ} \mathrm{C}$ corresponded to a faster motion of the molecules, and the strength of interaction was not enough to bind the AAI molecules on sorbents. Otherwise, high temperature inhibited the adsorption of AAI on sorbents through hydrophobic interactions [32]. Figures S6 and S7 showed the relationships between equilibrium concentration $C_{e}$ and adsorption amount $Q_{e}$ by fitting the data to the Langmuir model and the Freundlich model. The results showed that the initial concentration and temperatures played important roles in the adsorption process. In addition, according to the adsorption theory, the adsorption process of AAI on the sorbents was monolayer adsorption at the homogeneous surface.

The adsorption capacity of AAI on the three sorbents as a function of time at $25^{\circ} \mathrm{C}$ is shown in Figure 4. Also, the fit of pseudo-first-order and pseudo-second-order equations to the adsorption data are shown in Figures 4 and S8. The data suggested that the adsorption possibly included multi-diffusion processes. The amount of AAI adsorbed increased with time increasing, and higher initial concentration needed more time to reach the equilibrium.
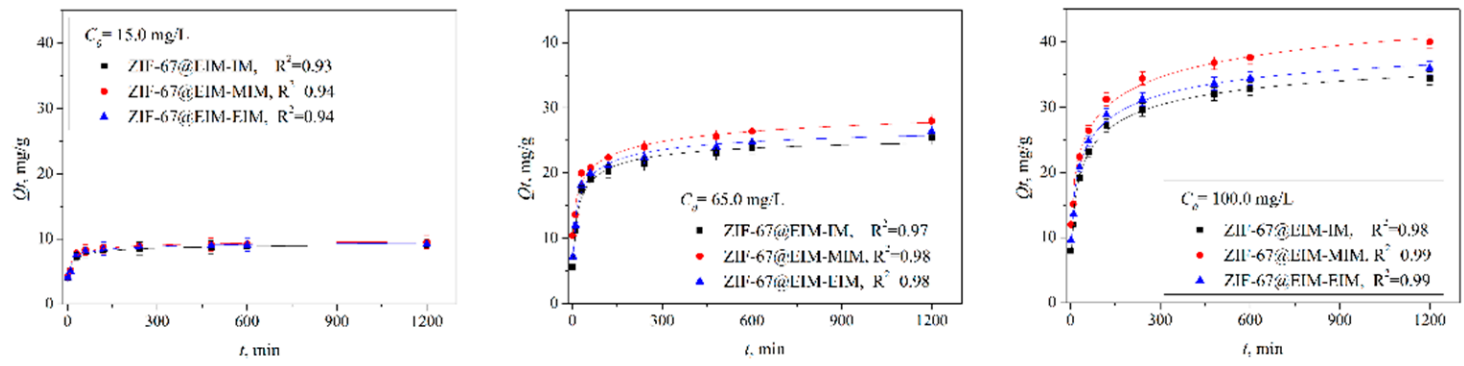

Figure 4. The adsorption of AAI onto three dual IL-immobilized ZIF-67 sorbents at $25^{\circ} \mathrm{C}$ with the pseudo-first-order model. 
From the theoretical model analysis, the Langmuir model fitted the experimental data better and exhibited a higher correlation coefficient than the Freundlich model. ZIF67@EIM-MIM showed the highest adsorption capacity of $50.88 \mathrm{mg} / \mathrm{g}$ and the optimized adsorption conditions were $25^{\circ} \mathrm{C}$ with $120 \mathrm{~min}$. To prove the optimum adsorption capacity of ZIF-67@EIM-MIM, the maximum adsorption amounts of ZIF-67, ZIF-67@Br, ZIF67@imidazole, ZIF-67@EIM-Cl and the other two immobilized sorbents were evaluated under the same conditions. The results showed in Figure 5 proved that the functionalization of IL can promote the adsorption performance obviously, especially ZIF-67@EIM-MIM with dual ILs.

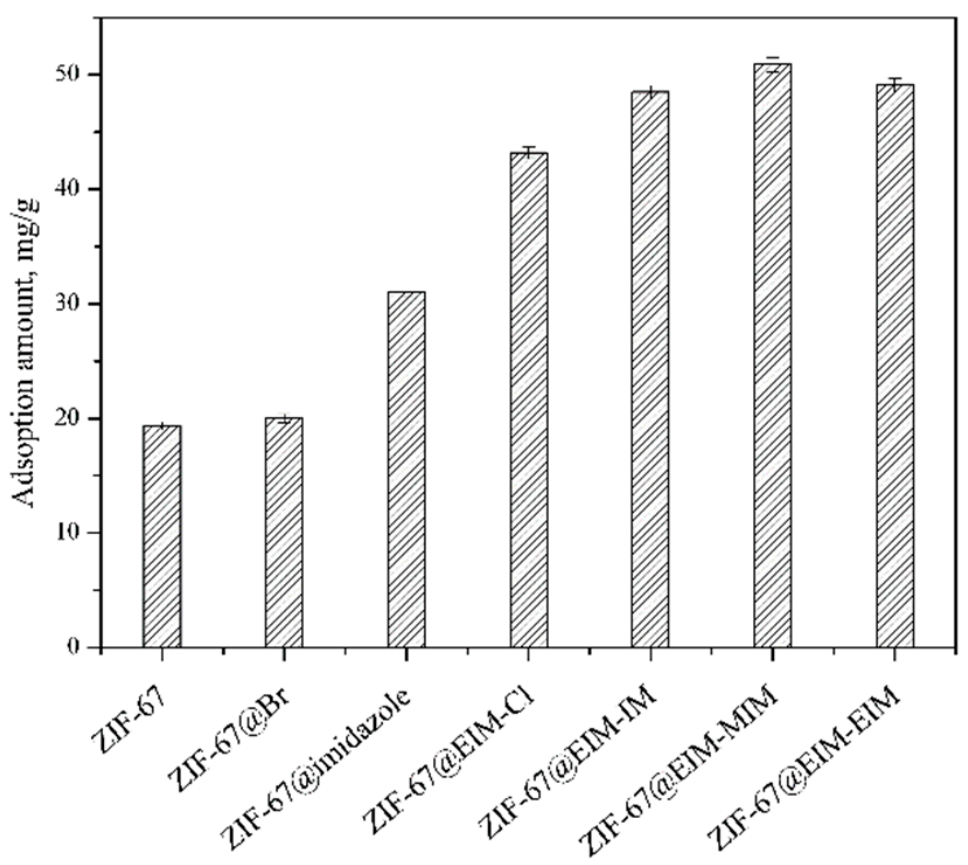

Figure 5. Maximum adsorption amounts of ZIF-67, ZIF-67@Br, ZIF-67@imidazole, ZIF-67@EIM-Cl, and three dual ILs-immobilized ZIF-67s.

\subsection{Solid-Phase Extraction of AAI from Real Sample}

After loading $3.0 \mathrm{~mL}$ of extracted solution onto the sorbent, the filter solution was collected and analyzed. Figure 6A,B,G showed the chromatograms of standard solution, extraction solution before and after loading. Compared (A) and (B), peak areas of interferences and AAI obviously decreased. It revealed that both interferences and AAI were adsorbed on the sorbent. Then the effects of the washing and elution solutions were assessed. Large amounts of non-polar and polar interference were washed out using hexane (Figure 6C), water (Figure 6D), and methanol (Figure 6E) because of weak interactions between these interference and sorbent. Therefore, the volume of these three solvents needed to be increased until no more interference was detected. Accordingly, $6.0 \mathrm{~mL}, 4.0 \mathrm{~mL}$ and $6.0 \mathrm{~mL}$ of hexane, water and methanol were applied, respectively. Finally, methanol/0.1 M aqueous $\mathrm{NaOH}(90.0: 10.0, v / v)$ with higher elution ability was applied, and $6.0 \mathrm{~mL}$ of it can remove all the adsorbed AAI from the sorbent (Figure 6F). The result proved that AAI was successfully separated from interferences and $0.02 \mathrm{mg}$ of AAI can be removed per gram of Fibraurea Recisa Pierre. 


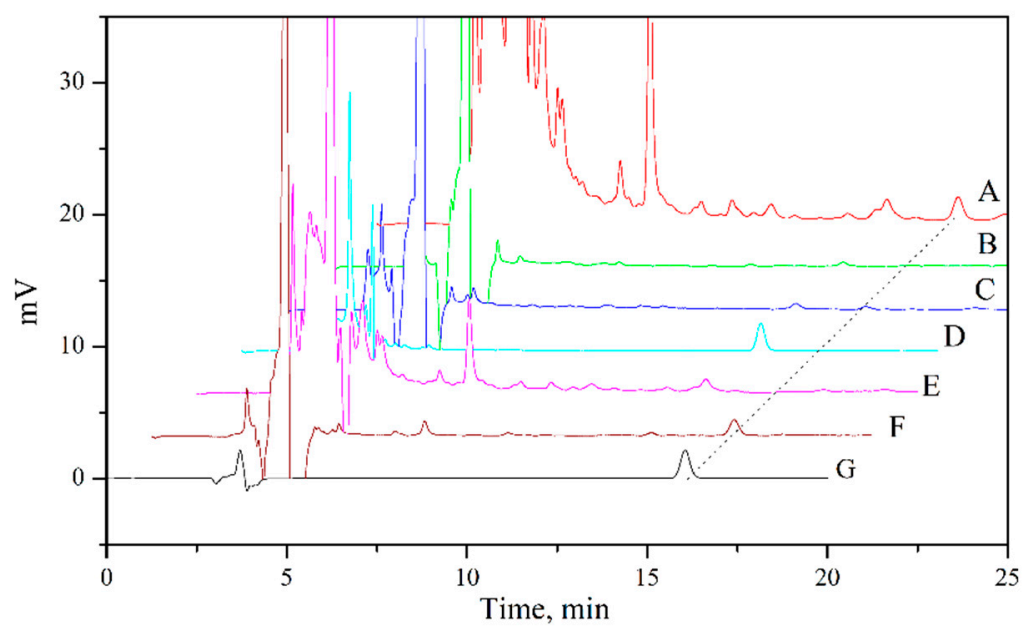

Figure 6. Chromatograms. (A) extracted solution, (B) solution after loading, (C) washing using hexane, (D) washing using water, (E) washing using methanol, (F) elution using methanol/0.10 M $\mathrm{NaOH}(90.00: 10.00, v / v),(G)$ standard solution.

\subsection{Validation}

The standard solution was diluted in methanol to obtain a series of solution with nine concentration levels 1.2, 15.0, 30.0, 45.0, 60.0, 75.0, 85.0, 100.0, 132.0 mg/L. The calibration curves were constructed using the chromatographic peak areas with three injection at each level. Good linearity of the calibration curves was obtained, and the correlation equation was $y=0.5 x-0.7\left(R^{2}=0.98\right)$ ( $y$ is the peak area and $x$ is the concentration in solution). Based on signal-to-noise ratios of 3 (LOD) and 10 (LOQ), the LOD and LOQ were $0.02 \mathrm{mg} / \mathrm{L}$ and $0.09 \mathrm{mg} / \mathrm{L}$, respectively.

Then, a certain concentration was spiked into Fibraurea Recisa Pierre extracted solution and analyzed to calculate the recoveries of SPE [33]. Moreover, the intra-day and the interday relative standard deviations (RSDs) were calculated by repeating the SPE process with exactly same conditions 5 times in the same day and injecting for 5 consecutive days. Good recoveries of $96.2-100.0 \%$ and RSDs of 3.5-4.0\% were obtained (Table 1 ). The satisfactory recoveries and RSD implied that this method was accurate and precise for analyzing AAI. To evaluate the reusability of ZIF-67@EIM-MIM, it was reused in SPE process, and after recycling seven times the recoveries of AAI were larger than $63.2 \%$.

Table 1. Recoveries and RSDs of AAI spiked into Fibraurea Recisa Pierre extract.

\begin{tabular}{|c|c|c|c|c|c|}
\hline \multirow{2}{*}{ AAI in Plant $(\mu \mathrm{g} / \mathrm{g})$} & \multirow{2}{*}{ Spiked $(\mu \mathrm{g} / g)$} & \multirow{2}{*}{ Found $(\mu \mathrm{g} / \mathrm{g})$} & \multirow{2}{*}{ Relative Recovery (\%) } & \multicolumn{2}{|c|}{ RSD (\%) } \\
\hline & & & & Intra-Day & Inter-Day \\
\hline \multirow{3}{*}{20.0} & 2.0 & $21.2 \pm 0.04$ & 96.2 & 3.5 & 3.9 \\
\hline & 20.0 & $40.0 \pm 0.03$ & 100.0 & 3.8 & 3.9 \\
\hline & 200.0 & $219.1 \pm 0.02$ & 99.6 & 4.0 & 4.0 \\
\hline
\end{tabular}

Additionally, ZIF-67@EIM-MIM was synthesized under the same conditions every two days and repeated for 5 times. The adsorption capacity (under the optimized adsorption condition: $25^{\circ} \mathrm{C}$ with $120 \mathrm{~min}$ ) and SPE process were repeated on each obtained sorbent. The rate of reproducibility is between $92.4-98.8 \%$ and the results revealed that the sorbent was reliable for the extraction sample.

The performance of proposed sorbent was compared with previous studies in Table 2. Original ZIF-67 was applied by Lin et al. to adsorb malachite green with a capacity of $240.0 \mathrm{mg} / \mathrm{g}$ [11]. Du et al. used the original ZIF-67 to adsorb 21 organic dyes, according to different size and functional groups, the capacities were in the range of $4.3-800.0 \mathrm{mg} / \mathrm{g}$ [34]. Liu et al. used sulfonated ZIF-67 to adsorb 9 organic dyes, the maximum capacity increased 
to $1250.0 \mathrm{mg} / \mathrm{g}$ [35]. Wei et al. immobilized ZIF-67 using 1-hexyl-3-methyl imidazolium chloride ionic liquid modified magnetic $\mathrm{Fe}_{3} \mathrm{O}_{4}\left(\mathrm{IL}_{-} \mathrm{Fe}_{3} \mathrm{O}_{4}\right)$ nanoparticles and hydroxylated multiwall carbon nanotubes (MWCNTs-OH), and the sorbent ZIF-67@MWCNTs-OH@IL$\mathrm{Fe}_{3} \mathrm{O}_{4}$ was applied in $\alpha$-chymotrypsin adsorption with capacity of $637.7 \mathrm{mg} / \mathrm{g}$ [36]. The results of two immobilized ZIF-67 sorbents approved that the capacity of immobilized ZIF-67 increased efficiently.

Table 2. Comparison of the proposed material with the previous studies.

\begin{tabular}{|c|c|c|c|c|c|c|c|}
\hline Sorbent & Targets & $\begin{array}{l}\text { Capacity } \\
(\mathrm{mg} / \mathrm{g})\end{array}$ & Recycles & $\begin{array}{c}\text { LOD } \\
(\mu \mathrm{g} / \mathrm{mL})\end{array}$ & Recovery (\%) & RSD (\%) & Ref. \\
\hline ZIF-67 & $\begin{array}{c}\text { Malachite } \\
\text { green }\end{array}$ & 240.0 & 4 & - & 95.0 & - & {$[11]$} \\
\hline ZIF-67 & Organic dyes & $4.3-800.0$ & - & - & $62.4-86.8$ & - & [34] \\
\hline Sulfonated ZIF-67 & Organic dyes & $94.3-1250.0$ & 5 & - & 2.9-92.9 & - & [35] \\
\hline $\begin{array}{c}\text { ZIF-67@MWCNT- } \\
\text { OH@IL-Fe } 3 \mathrm{O}_{4}\end{array}$ & Chymotrypsin & 637.7 & 5 & - & $\sim 86$ & $0.1-1.2$ & [36] \\
\hline MIP & AAI & 1.3 & 6 & 0.06 & 91.5 & 4.2 & {$[37]$} \\
\hline MIS & AAI & 8.1 & - & 0.04 & - & - & [38] \\
\hline Sil@IM-BIM & AAI & 16.7 & - & - & 70.0-110.6 & $3.5-9.1$ & [24] \\
\hline $\mathrm{SiO}_{2} @ \mathrm{CNT} / \mathrm{Fe}_{3} \mathrm{O}_{4}$ & AAI & 24.5 & 5 & 0.05 & 92.7-98.4 & $1.7-3.9$ & [39] \\
\hline UIO-66-NH $\mathrm{NH}_{2} @ \mathrm{NMA}$ & AAI & 35.4 & - & 0.1 & $91.1-106.5$ & $0.9-6.1$ & [33] \\
\hline CMCs@CS & AAI & 77.72 & - & 0.1 & $73.6-77.7$ & $0.8-4.5$ & [40] \\
\hline ZIF-67@EIM-MIM & AAI & 50.9 & 7 & 0.02 & 82.9-90.1 & $3.5-4.0$ & This work \\
\hline
\end{tabular}

To separate AAI, several composite sorbents were investigated. Molecular imprinted polymer (MIP) was a common sorbent and Xiao et al. applied the MIP to remove AAI from a plant extract; however, the capacity was only $1.3 \mathrm{mg} / \mathrm{g}$ [37]. Silica, as a stable substrate, was immobilized by various functional groups. Wang et al. developed a dummy molecularly imprinted silica (MIS) with a capacity of $8.1 \mathrm{mg} / \mathrm{g}$ [38]. Fang et al. immobilized silica with imidazolium chloride-ethylimidazolium chloride (Sil@IM-BIM), and the sorbent was obtained a capacity of $16.7 \mathrm{mg} / \mathrm{g}$ [24]. When magnetic carbon nanotubes with adenine was used to immobilize silica, the capacity of obtained sorbent SiO2-A@CNT/Fe3O4 increased to $24.5 \mathrm{mg} / \mathrm{g}$ [39]. UIO-66, as another MOF material, was composited with $\mathrm{N}$ methylolacrylamide (NMA) by Zhang et al. and it was used to separate AAI as a monolith sorbent with a capacity of $35.4 \mathrm{mg} / \mathrm{g}$ [33]. Shu et al. prepared a chitosan modified carbon microcoils (CMCs@CS), the sorbent exhibited a good binding ability $(77.7 \mathrm{mg} / \mathrm{g})$ and satisfactory selectivity [40]. Overall, the sorbent developed in the present study exhibited higher adsorption capacity.

\section{Conclusions}

In this study, three dual ILs-immobilized ZIF-67 sorbents were prepared and applied in SPE to remove AAI from Fibraurea Recisa Pierre which was used as a herbal medicine to treat cough. Using the analysis of adsorption models, the adsorption capacities of immobilized sorbents were efficiently increased, and the highest amount of $50.9 \mathrm{mg} / \mathrm{g}$ was obtained on ZIF-67@EIM-MIM at $25^{\circ} \mathrm{C}$ within $120 \mathrm{~min}$ among the three sorbents. When ZIF-67@EIM-MIM was applied in SPE, $6.0 \mathrm{~mL}, 4.0 \mathrm{~mL}$ and $6.0 \mathrm{~mL}$ of hexane, water, and methanol can wash all interferences and $6.0 \mathrm{~mL}$ of methanol/0.1 M aqueous $\mathrm{NaOH}$ $(90.0: 10.0, v / v)$ can remove all adsorbed AAI. The provided experimental data revealed that ZIF-67@EIM-MIM was a potential sorbent to remove AAI from herbal plant, and it could be an ideal material for the pretreatment of herbal plant extracted solution containing AAI.

Supplementary Materials: The following are available online at https:/ /www.mdpi.com/22978739/8/2/22/s1, Figure S1: SEM of ZIF-67@Imidazole, ZIF-67@EIM-IM and ZIF-67@EIM-EIM, Figure S2: FT-IR of ZIF-67, ZIF-67@EIM-Cl, ZIF-67@EIM-IM, ZIF-67@EIM-MIM and ZIF-67@EIMEIM, Figure S3: TGA analysis of ZIF-67, ZIF-67@EIM-Cl and ZIF-67@EIM-MIM, Figure S4: XRD 
spectrograms of ZIF-67, ZIF-67@imidazole and ZIF-67@EIM-MIM, Figure S5: The relationships between initial concentration $\left(C_{0}\right)$ and adsorption efficiency $(E R \%)$ of $\mathrm{AAI}$ on three sorbents at 5 , 25, 35 and $45^{\circ} \mathrm{C}$, Figure S6: The Langmuir model for AAI adsorption onto ZIF-67@EIM-IM, ZIF67@EIM-MIM and ZIF-67@EIM-EIM at 5, 25, 35 and $45^{\circ} \mathrm{C}$, Figure S7: The Freundlich model for AAI adsorption onto ZIF-67@EIM-IM, ZIF-67@EIM-MIM and ZIF-67@EIM-EIM at 5, 25, 35 and $45^{\circ} \mathrm{C}$, Figure S8: The adsorption of AAI onto three dual IL-immobilized ZIF- 67 sorbents at $25{ }^{\circ} \mathrm{C}$ with the pseudo-second-order model.

Author Contributions: Conceptualization, X.Y. and M.T.; methodology, P.C.; software, P.C.; validation, P.C., X.L. and M.T.; writing-original draft preparation, P.C., X.L. and M.T.; writing-review and editing, X.Y. and M.T.; supervision, M.T. All authors have read and agreed to the published version of the manuscript.

Funding: This research was funded by the National Natural Science Foundation of China (No. 51503020 and No. 51472034).

Institutional Review Board Statement: Not applicable.

Informed Consent Statement: Not applicable.

Data Availability Statement: Data is contained within the article and supplementary material.

Conflicts of Interest: The authors declare no conflict of interest.

\section{References}

1. Lin, C.; Chang, W.; Lee, J.; Chang, T.; Huang, Y.; Hirasaki, Y.; Chen, H.; Imai, K.; Chen, S. Proteomics analysis of altered proteins in kidney of mice with aristolochic acid nephropathy using the fluorogenic derivatization-liquid chromatography-tandem mass spectrometry method. Biomed. Chromatogr. 2018, 32, 1-9. [CrossRef] [PubMed]

2. Wu, L.; Sun, W.; Wang, B.; Zhao, H.; Li, Y.; Cai, S.; Xiang, L.; Zhu, Y.; Yao, H.; Song, J.; et al. An integrated system for identifying the hidden assassins in traditional medicines containing aristolochic acids. Sci. Rep. 2015, 5, 1-10. [CrossRef] [PubMed]

3. Fang, L.; Tian, M.; Row, K.H.; Yan, X.; Xiao, W. Isolation of aristolochic acid I from herbal plant using molecular imprinted polymer composited ionic liquid-based zeolitic imidazolate framework-67. J. Sep. Sci. 2019, 42, 3047-3053. [CrossRef] [PubMed]

4. Gutiérrez-Serpa, A.; Pacheco-Fernández, I.; Pasán, J.; Pino, V. Metal-organic frameworks as key materials for solid-phase microextraction devices-A review. Separations 2019, 6, 47. [CrossRef]

5. Rocío-Bautista, P.; Taima-Mancera, I.; Pasán, J.; Pino, V. Metal-organic frameworks in green analytical chemistry. Separations 2019, 6, 33. [CrossRef]

6. Zhong, G.; Liu, D.; Zhang, J. The application of ZIF-67 and its derivatives: Adsorption, separation, electrochemistry and catalysts. J. Mater. Chem. A 2018, 6, 1887-1899. [CrossRef]

7. Phuoc, N.M.; Jung, E.; Tran, N.A.T.; Lee, Y.; Yoo, C.; Kang, B.; Cho, Y. Enhanced desalination performance of capacitive deionization using nanoporous carbon derived from ZIF-67 metal organic frameworks and CNTs. Nanomaterials 2020, 10 , 2091. [CrossRef]

8. Tang, J.; Jiang, S.; Liu, Y.; Zheng, S.; Bai, L.; Guo, J.; Wang, J. Electrochemical determination of dopamine and uric acid using a glassy carbon electrode modified with a composite consisting of a Co(II)-based metalorganic framework (ZIF-67) and graphene oxide. Microchim. Acta 2018, 185, 1-11. [CrossRef]

9. Haldorai, Y.; Choe, S.R.; Huh, Y.S.; Han, Y.K. A composite consisting of microporous carbon and cobalt(III) oxide and prepared from zeolitic imidazolate framework-67 for voltammetric determination of ascorbic acid. Microchim. Acta 2018, 185, 1-10. [CrossRef]

10. Li, Q.; Guo, J.; Zhu, H.; Yan, F. Space-confined synthesis of ZIF- 67 nanoparticles in hollow carbon nanospheres for $\mathrm{CO}_{2}$ adsorption. Small 2019, 15, 1-8. [CrossRef]

11. Lin, K.Y.A.; Chang, H.A. Ultra-high adsorption capacity of zeolitic imidazole framework-67 (ZIF-67) for removal of malachite green from water. Chemosphere 2015, 139, 624-631. [CrossRef] [PubMed]

12. Yang, Q.; Lu, R.; Ren, S.; Zhou, H.; Wu, Q.; Zhen, Y.; Chen, Z.; Fang, S. Magnetic beads embedded in poly(sodium-pstyrenesulfonate) and ZIF-67: Removal of nitrophenol from water. J. Solid State Chem. 2018, 265, 200-207. [CrossRef]

13. Yang, Q.; Ren, S.; Zhao, Q.; Lu, R.; Hang, C.; Chen, Z.; Zheng, H. Selective separation of methyl orange from water using magnetic ZIF-67 composites. Chem. Eng. J. 2018, 333, 49-57. [CrossRef]

14. Yang, Q.; Lu, R.; Ren, S.; Chen, C.; Chen, Z.; Yang, X. Three dimensional reduced graphene oxide/ZIF-67 aerogel: Effective removal cationic and anionic dyes from water. Chem. Eng. J. 2018, 348, 202-211. [CrossRef]

15. Wang, Z.; Ren, D.; Yu, H.; Jiang, S.; Zhang, S.; Zhang, X. Study on improving the stability of adsorption-encapsulation immobilized Laccase@ZIF-67. Biotechnol. Rep. 2020, 28, 1-8. [CrossRef] [PubMed]

16. Liang, C.; Zhang, X.; Feng, P.; Chai, H.; Huang, Y. ZIF-67 derived hollow cobalt sulfide as superior adsorbent for effective adsorption removal of ciprofloxacin antibiotics. Chem. Eng. J. 2018, 344, 95-104. [CrossRef] 
17. Yang, Y.; Yan, X.; Hua, X.; Feng, R.; Zhou, M.; Cui, W. Development of zeolitic imidazolate framework-67 functionalized Co-Al LDH for $\mathrm{CO}_{2}$ adsorption. Colloids Surf. 2018, 552, 16-23. [CrossRef]

18. Zhao, H.; Wang, Y.; Zhao, L. Magnetic nanocomposites derived from hollow ZIF-67 and core-shell ZIF-67@ZIF-8: Synthesis, properties, and adsorption of Rhodamine B. Eur. J. Inorg. Chem. 2017, 2017, 4110-4116. [CrossRef]

19. Knebel, A.; Wulfert-Holzmann, P.; Friebe, S.; Pavel, J.; Strauß, I.; Mundstock, A.; Steinbach, F.; Caro, J. Hierarchical nanostructures of metal-organic frameworks applied in gas separating ZIF-8-on-ZIF-67 membranes. Chem. A Eur. J. 2018, 24, 5728-5733. [CrossRef]

20. Han, Y.; Yang, C.; Zhou, Y.; Han, D.; Yan, H. Ionic liquid-hybrid molecularly imprinted material-filter solid-phase extraction coupled with HPLC for determination of 6-benzyladenine and 4-chlorophenoxyacetic acid in bean sprouts. J. Agric. Food Chem. 2017, 65, 1750-1757. [CrossRef] [PubMed]

21. Yang, F.; Feng, P. Densities and viscosities of ionic liquid with organic solvents. Appl. Sci. 2020, 10, 8342. [CrossRef]

22. Wieszczycka, K.; Filipowiak, K.; Buchwald, T.; Nowicki, M. Microcapsules containing task-specific ionic liquids for Zn(II) and $\mathrm{Cu}(\mathrm{II})$ recovery from dilute aqueous solutions. Sep. Purif. Technol. 2020, 250, 1-18. [CrossRef]

23. Tian, M.; Fang, L.; Yan, X.; Xiao, W.; Row, K.H. Determination of heavy metal ions and organic pollutants in water samples using ionic liquids and ionic liquid-modified sorbents. J. Anal. Methods Chem. 2019, 2019, 1-19. [CrossRef] [PubMed]

24. Fang, L.; Tian, M.; Yan, X.; Xiao, W.; Row, K.H. Dual ionic liquid-immobilized silicas for multi-phase extraction of aristolochic acid from plants and herbal medicines. J. Chromatogr. A 2019, 1592, 31-37. [CrossRef]

25. Fang, L.; Tian, M.; Yan, X.; Xiao, W. Isolation of aflatoxin B1 from moldy foods by solid-phase extraction combined with bifunctional ionic liquid-based silicas. J. Anal. Methods Chem. 2018, 2018, 1-7. [CrossRef]

26. Khan, N.A.; Hasan, Z.; Jhung, S.H. Ionic liquids supported on metal-organic frameworks: Remarkable adsorbents for adsorptive desulfurization. Chem. A Eur. J. 2014, 20, 376-380. [CrossRef]

27. Sarker, M.; Ahmed, I.; Jhung, S.H. Adsorptive removal of herbicides from water over nitrogen-doped carbon obtained from ionic liquid@ZIF-8. Chem. A Eur. J. 2017, 323, 203-211. [CrossRef]

28. Liu, S.; Liu, J.; Hou, X.; Xu, T.; Tong, J.; Zhang, J.; Ye, B.; Liu, B. Porous liquid: A stable ZIF-8 colloid in ionic liquid with permanent porosity. Langmuir 2018, 34, 3654-3660. [CrossRef] [PubMed]

29. Gutiérrez-Serpa, A.; Napolitano-Tabares, P.I.; Šulc, J.; Pacheco-Fernández, I.; Pino, V. Role of ionic liquids in composites in analytical sample preparation. Separations 2020, 7, 37. [CrossRef]

30. Lin, K.-Y.A.; Lee, W.-D. Self-assembled magnetic graphene supported ZIF-67 as a recoverable and efficient adsorbent for benzotriazole. Chem. Eng. J. 2016, 284, 1017-1027.

31. Chan, C.; Liu, Y.; Pavlović, N.M.; Chan, W. Aristolochic acids: Newly identified exposure pathways of this class of environmental and food-borne contaminants and its potential link to chronic kidney diseases. Toxics 2019, 7, 14. [CrossRef]

32. Saffarionpour, S.; Tam, S.S.; Wielen, L.A.M.; Brouwer, E.; Ottens, M. Influence of ethanol and temperature on adsorption of flavor-active esters on hydrophobic resins. Sep. Purif. Technol. 2019, 210, 219-230. [CrossRef]

33. Zhang, M.; Liu, H.; Han, Y.; Bai, L.; Yan, H. On-line enrichment and determination of aristolochic acid in medicinal plants using a MOF-based composite monolith as adsorbent. J. Chromatogr. B 2020, 1159, 122343. [CrossRef]

34. Du, X.; Wang, C.; Liu, J.; Zhao, X.; Zhong, J.; Li, Y.; Li, J.; Wang, P. Extensive and selective adsorption of ZIF-67 towards organic dyes: Performance and mechanism. J. Colloid Interface Sci. 2017, 506, 437-441. [CrossRef]

35. Liu, Y.; Lin, D.; Yang, W.; An, X.; Sun, A.; Fan, X.; Pan, Q. In situ modification of ZIF-67 with multi-sulfonated dyes for great enhanced methylene blue adsorption via synergistic effect. Microporous Mesoporous Mater. 2020, 303, 1-9. [CrossRef]

36. Wei, X.; Wang, Y.; Chen, J.; Xu, P.; Zhou, Y. Preparation of ionic liquid modified magnetic metal-organic frameworks composites for the solid-phase extraction of $\alpha$-chymotrypsin. Talanta 2018, 182, 484-491. [CrossRef] [PubMed]

37. Xiao, Y.; Xiao, R.; Tang, J.; Zhu, Q.; Li, X.; Xiong, Y.; Wu, X. Preparation and adsorption properties of molecularly imprinted polymer via RAFT precipitation polymerization for selective removal of aristolochic acid I. Talanta 2017, 162, 415-422. [CrossRef]

38. Wang, L.; Zhang, C.; Chen, Y.; Deng, Q.; Wang, S. Dummy molecularly imprinted silica materials for effective removal of aristolochic acid I from kaempfer dutchmanspipe root extract. Microchem. J. 2020, 152, 1-7. [CrossRef]

39. Shu, H.; Chen, G.; Wang, L.; Cui, X.; Wang, Q.; Li, W.; Chang, C.; Guo, Q.; Luo, Z.; Fu, Q. Adenine-coated magnetic multiwalled carbon nanotubes for the selective extraction of aristolochic acids based on multiple interactions. J. Chromatogr. A 2020, 1627, 1-9. [CrossRef]

40. Shu, H.; Ge, Y.; Xu, X.; Guo, P.; Luo, Z.; Du, W.; Chang, C.; Liu, R.; Fu, Q. Hybrid-type carbon microcoil-chitosan composite for selective extraction of aristolochic acid I from Aristolochiaceae medicinal plants. J. Chromatogr. A 2018, 1561, 13-19. [CrossRef] 